\title{
¿Informalidad o dualismo en las manufacturas mexicanas?*
}

\author{
Alicia Puyana** y José Romero***
}

\section{Resumen}

Este trabajo explora la estructura del sector manufacturero mexicano, diferenciando a las empresas por su tamaño, según el número de trabajadores y por su evolución entre 1994 y 2008, periodo en el cual se habían consolidado las reformas instrumentadas como respuesta a la crisis de la deuda y a los cambios introducidos con la firma del Tratado de Libre Comercio de América del Norte (TLCAN); analiza en qué medida la trayectoria del sector escindido en dos universos - el de las empresas de menos de 15 trabajadores o sector informal, y las demás, permite deducir, de acuerdo con el modelo de Lewis, que la economía mexicana aún permanece en la etapa de crecimiento clásico de oferta ilimitada de mano de obra. El lento crecimiento de la economía y de las inversiones por trabajador, es una de las explicaciones de esta situación. Los datos permiten afirmar que éste es el caso.

\begin{abstract}
The paper analyzes the changes in the structure of informal manufactures sector, as presented by the differences in the contribution to employment, value added, gross capital formation and productivity of the production units differentiated by their size. The study covers the period 1994-2008, during which the structural reforms of mid eighties and the North American Free Trade Agreement had consolidated. The results confirm that the Mexican economy conforms to the Lewis Model of classical growth with unlimited supply of labour, low productivity and low wages.
\end{abstract}

Palabras clave: México, manufacturas, productividad, economía informal. Key words: Mexico, manufactures, productivity, informal economy.

* Los autores agradecen los valiosos comentarios de dos dictaminadores anónimos que contribuyeron a afinar la argumentación de este trabajo. Los errores y omisiones son de exclusiva responsabilidad de los autores.

** Profesora investigadora de la Flacso México.

*** Profesor investigador de El Colegio de México. 
A

pesar de la liberalización de los mercados de bienes y servicios, y en algunos países, del mercado laboral, y a despecho de la expansión de las exportaciones de manufacturas, no menos de siete de cada diez empleos generados, desde los años ochenta, en América Latina, México incluido, son informales, y la mayoría de ellos corresponden al sector servicios. El efecto de esta trayectoria del mercado laboral es la agudización del dualismo económico y la desigualdad social. El abultamiento de la informalidad, y del dualismo resultante, ocurre pese al "relajamiento de los mercados" inducido por las reformas que ofrecían la eliminación del "mercantilismo" de la sustitución de importaciones, que al garantizar, a unos pocos empresarios, rentas de privilegio, impedía a la mayoría transitar hacia a la modernidad.

Hoy parece evidente que ni en los periodos de gran dinamismo, la economía mexicana logra integrar a la producción moderna a toda la población en edad de trabajar que ingresa al mercado laboral. En este sentido, podemos sugerir que la economía mexicana acusa, desde los años ochenta, un "déficit de crecimiento", así como la contracción de la intensidad laboral del producto, la cual varía según los sectores y el nivel de desagregación en que se trabaje. Los aumentos de productividad, ya sea manteniendo constante el producto o, como ha sucedido en México, con bajas tasas de crecimiento de éste, se han traducido en menor absorción de trabajo. Entre 1994 y 2010, la productividad laboral del sector manufacturero total fue baja, como se verá más adelante, y no es homogénea en todas las ramas que componen el sector. No obstante, y en términos agregados, la productividad de las manufacturas ha sido más dinámica que en la agricultura o los servicios, lo cual es un factor importante para comprender la trayectoria del sector informal. Este comportamiento de la economía y del mercado laboral, resulta del limitado dinamismo del sector manufacturero sumado al reemplazo de trabajo por capital y del valor agregado nacional por importado. Esta combinación de factores es particularmente preocupante en las manufacturas, responsables del avance de las exportaciones mexicanas, al representar más de $80 \%$ de las ventas externas del país. La mayoría de estas exportaciones son generadas en la Industria Maquiladora de Exportación (IME) y en programas similares, y el fragmento que se procesa en México, si bien es intensivo en mano de obra, representa un segmento pequeño con relación al valor total del producto exportado. El valor agregado local exportado está compuesto, casi en su totalidad, por salarios. El trabajo generado por la IME es de menor calidad, y sus efectos sobre otros sectores tienen lugar por eslabonamientos reducidos. 
La mexicana es una economía abierta; en ella, los flujos internacionales de bienes, capitales y servicios son prácticamente libres, mientras que el movimiento laboral internacional es penalizado. Todo ello ha elevado la movilidad del capital y su costo en relación con el trabajo, y ha acelerado el avance de la informalidad y el empleo precario. Es importante recordar que el dualismo no se concibe como la coexistencia de dos fracciones inconexas o autónomas de la economía, sino como dos partes de un todo, que se vinculan y retroalimentan por diferentes canales. Una fracción es de baja productividad y precariamente dotada de capital; la otra, moderna, altamente eficiente y con disponibilidad de tecnología de punta, en ocasiones provista por inversionistas foráneos.

En este trabajo exploramos la evolución de la estructura del sector manufacturero, desde la perspectiva del tamaño de las empresas, con miras a poner de manifiesto la persistencia del sector informal y la consolidación de un dualismo sectorial, con las secuelas de baja productividad y bajos salarios para todo el sector. Se limita el análisis al mercado laboral urbano, ya que la informalidad citadina es el receptáculo de los miles de trabajadores rurales que abandonan el campo y nutren la oferta de mano de obra a mayor velocidad que la creación de empleos en el sector formal y la dotación de capital en éste.

La discusión sobre la economía informal ha sido amplia, y las definiciones del término han sido múltiples; nosotros nos concentraremos en la que circunscribe la informalidad al empleo y la producción en unidades de menos de quince trabajadores, como se establece en los censos del INEGI (1995 y 2009a) y en las Encuestas de Micronegocios INEGI (2009b). Esta acepción permite explorar el dualismo en las unidades productivas manufactureras, lo mismo que su vínculo con la formación de capital, la productividad y las remuneraciones. Es claro que esta delimitación puede reducir el tamaño de la informalidad y su impacto sobre la economía; sin embargo, permite ahondar en la estructura del sector manufacturero, cuyo conocimiento es considerado central para acelerar el crecimiento de la productividad laboral y total de los factores en toda la economía, y para estimular el avance tecnológico y el ingreso.

Este artículo explora la relación entre informalidad y dualismo en las manufacturas mexicanas, desde el punto en que, por diversas razones expuestas en otros trabajos (Puyana, 2011; Puyana y Romero, 2009), se estancó el avance del empleo formal iniciado en los años cuarenta y se inició el repunte de la informalidad. Esta reversión de la estructura del mercado laboral no se desactivó, como se esperaba, ni con la liberalización de la economía ni con el TLCAN.

En este trabajo se pondrá especial énfasis en la exploración de la estructura de los establecimientos manufactureros, y observaremos si, en alguna 
medida, dicha estructura se ajusta al modelo de Lewis (1958 y 1979); el planteamiento es que en el sector manufacturero coexisten los dos sectores que se aproximan a los descritos por Lewis: uno moderno y otro no moderno de subsistencia. El primero arroja superiores grados de productividad y tasas de rentabilidad, mientras que en el segundo la productividad es muy escasa. Proponemos que el patrón de crecimiento de México de los últimos 30 años, ha limitado la capacidad del sector moderno urbano para absorber el crecimiento de la oferta laboral, tanto la que se desplaza de la agricultura como el incremento de la fuerza laboral. En este sentido, México aún se encontraría en la etapa de expansión clásica con excedentes de mano de obra, ubicados unos en el sector rural y otros en el sector informal urbano.

A diferencia de otros estudios, éste concentra el análisis en el sector informal urbano manufacturero. No explora, como otros trabajos, las características personales de los trabajadores informales, sino la composición y trayectoria del sector, a partir del tamaño de las unidades productivas manufactureras, es decir, de las vinculadas a un sector claramente transable, y no al sector servicios, que es el normalmente analizado al estudiar la informalidad.

Para identificar el objeto de estudio, se parte de la definición de informalidad como la presenta el INEGI (2003), vinculada a unidades de menos de 15 trabajadores, límite que permite establecer el corte por tamaño de empresas resultante de los Censos Económicos y Encuestas. Resultados Definitivos, 1994 y 2009a. Para establecer una indispensable coherencia, se compararon los datos obtenidos de estos Censos con los que suministra la Encuesta Nacional de Micronegocios INEGI (2009b), y se confirmó su coincidencia. Las características que INEGI atribuye en las dos bases a prácticamente todos los micronegocios y a los establecimientos informales, son similares, y se podría argüir que corresponden a un mismo universo. Estas características se acercan a las que Lewis y otros investigadores atribuyen al sector no moderno o de subsistencia. De ahí que sea válido suponer que la coexistencia de establecimientos manufactureros con menos de 15 trabajadores al lado de empresas de mayor tamaño, podría tomarse como indicio de dualismo sectorial.

La estructura de las manufacturas mexicanas está profundamente escindida en dos sectores que se afectan mutuamente, en simbiosis permanente; dos sectores que, en los términos de Lewis, pueden ser descritos del siguiente modo: por una parte, el sector no moderno de las micro y pequeñas empresas, que son unidades productivas de menos de 15 trabajadores, con productividad e ingresos bajos, salarios no rígidos y bajos costos de entrada; y por el otro, el sector moderno de las grandes empresas, con mayor 
productividad y salarios rígidos. El primer grupo se nutre de la migración del campo y alimenta la oferta laboral para el segundo. Nuestra hipótesis es que la lenta tasa de inversión en el sector manufacturero formal, especialmente en las unidades más grandes, y el limitado crecimiento del producto, son factores que reproducen el dualismo. Estos efectos se deben, en parte, a que la revaluación cambiaria y la liberalización comercial, denominada apertura, han limitado las oportunidades de inversión, reducido la integración de valor agregado nacional y creado las condiciones para la permanencia del dualismo, cuando no de su agudización. Esta realidad se agrava por el elevado grado de monopolización de la economía mexicana, que limita el funcionamiento de los mercados. A estos hechos podría añadirse el crecimiento de la PEA y el cambio en la composición etaria de la sociedad, factores que incrementan la oferta de trabajo y más que ser, en la economía mexicana, un "bono demográfico", se convierten en una oferta ilimitada de mano de obra sin que exista la demanda equivalente, como lo sugieren Moreno y Ros, 2009.

Para desarrollar los anteriores puntos, en este trabajo se parte de las conclusiones extraídas de anteriores trabajos propios, en los que se analizan, primero, las causas de la baja tasa de inversión en la economía general, y, segundo, la dinámica del sector informal, aplicando el modelo de Lewis relativo al desarrollo con oferta abundante de mano de obra (Puyana y Romero, 2010 y 2011). El presente estudio se organiza como sigue. En la segunda sección se discute la conceptualización de la informalidad a partir de la creación de la Organización Internacional del Trabajo, allá por 1913, y de sus desarrollos en México, y repasa los aportes de Lewis sobre el dualismo económico. La tercera analiza, a grandes rasgos, la evolución del empleo informal en México desde la creación del Instituto Mexicano del Seguro Social, e identifica algunas etapas importantes en esta trayectoria, señalando la distribución de la informalidad urbana entre el sector servicios y el de manufacturas. La cuarta sección describe la informalidad en las manufacturas y presenta la estructura sectorial por tamaño de empresas, indicando la diferente trayectoria de cada categoría de empresas en variables cuantitativas - número de empresas y trabajadores, e inversión por trabajador - y cualitativas - productividad y remuneraciones medias. Este apartado incluye la aplicación del Índice Herfindahl y un ejercicio de correlaciones simples entre el tamaño de las empresas y las inversiones, y entre éstas y la trayectoria de la productividad y las remuneraciones. En la quinta sección se presentan las conclusiones. 


\section{Sobre informalidad y dualismo}

\subsection{Algunos conceptos básicos sobre informalidad}

En otro trabajo (Puyana y Romero, 2011) discutimos la trayectoria de la definición y la medición de la informalidad, y los aportes de Lewis a la comprensión del desarrollo; y aplicamos su modelo de oferta laboral perfectamente elástica a las condiciones de México desde las reformas circa 1986. Aquí presentamos una síntesis de las corrientes analíticas más conocidas y un resumen de algunos de los más recientes estudios sobre el tema en México.

Desde la disciplina económica, podemos agrupar en tres las grandes vertientes de análisis del papel de la economía informal en el desarrollo económico: la romántica, la parasitaria y la del dualismo. Las interpretaciones romántica y parasitaria tienen coincidencias con enfoques enmarcados en el institucionalismo, y la del dualismo, con los de corte estructuralista, según lo plantean La Porta et al. (2009). En lo que respecta a la concepción parasitaria, la decisión de establecerse y permanecer en la informalidad sólo busca evadir impuestos y demás costos de transacción derivados de la acción del Estado. La informalidad ejerce en esta área una competencia desleal con las unidades productivas formales, reduciendo el mercado de éstas, minando su productividad y frenando el progreso económico. Por lo tanto, la vertiente parasitaria es causa, no consecuencia, de la baja productividad económica. En la orilla opuesta se encuentra la vertiente romántica del análisis institucionalista, iniciada por De Soto (1987), para quien la informalidad es también una respuesta racional al exceso de regulación gubernamental, que otorga privilegios y crea rentas a favor de unos pocos, los más ricos y poderosos. Al desaparecer la regulación, se eliminaría la informalidad y se garantizaría el crecimiento económico; por otra parte, la existencia de mercados perfectamente competitivos permitiría la conversión de los trabajadores informales en modernos empresarios medianos y competitivos. Soto propone que de la reducción de la regulación surgirían, en los países en desarrollo, sociedades democráticas.

La versión estructuralista o dualista, inspirada en la propuesta de Lewis (1954 y 1979) sobre el desarrollo, parte de la segmentación del mercado laboral urbano en dos fragmentos aislados por la calidad del empleo y la productividad marginal de éste. Esta división configura el dualismo, es decir, un mercado laboral urbano donde conviven el sector moderno, con salarios superiores y rígidos, y el sector tradicional, con salarios menores y flexibles y con alta movilidad por la inexistencia de barreras de entrada 
(véase Banerjee, 1983; Daniels, 2004; Galli y Kucera, 2004). El sector no moderno, o informal - según la ampliación que el propio Lewis hiciera en 1979 - , se compone de unidades productivas pequeñas e ineficientes cuya administración es precaria o inexistente, y de una reducida dotación de capital. En estas condiciones, es improbable su evolución hacia la formalidad, como lo propone De Soto. El sector moderno se nutre de la fuerza laboral que abandona la agricultura por las sugestivas condiciones laborales del sector urbano moderno, percibidas como superiores a las existentes en el sector agropecuario, y por los incrementos de la población en edad de trabajar. ${ }^{1}$ Se plantea, en la interpretación dualista de la informalidad, que hay una relación estrecha entre la economía informal y la formal. La función de la primera es doble: propiciar que el sector formal moderno absorba la mano de obra excedente del sector informal, y servir, en el mejor de los casos - según las conclusiones de Portes, Castells, Benton y Roberts (1989) - , como la extensión del aparato productivo formal que permite corregir su inflexibilidad institucional. La informalidad urbana, por lo tanto, no afecta la opción del empleo formal, pues se asume que hay perfecta movilidad entre los dos sectores, como lo sugieren Todaro (1969), Banerjee (1983), Maloney (1997; 2004), Levy (2008), Fiess et al., (2002). Lo importante es no concebir los dos segmentos como unidades totalmente aisladas, sin puntos de encuentro. Según Daniels (2004), muchas actividades consideradas formales son informales, y de acuerdo con Schneider y Enste (2000), cerca de un tercio del ingreso informal es gastado en la economía formal. Debido a la emigración y a la rápida urbanización de la población, el crecimiento del sector informal urbano (que equivale en efecto al traslado hacia las ciudades del dualismo) es inevitable, pues la evidencia muestra que éste es la principal fuente de empleos (Barnerjee, 1983; Sethuraman, 1992; Escaith 2006). Estos autores coinciden con lo propuesto por Lewis (1979, al sugerir que no todo migrante puede vincularse al sector moderno de la economía urbana, ya que las fuentes de trabajo las generan, sobre todo, los micronegocios, los trabajadores por cuenta propia y los trabajadores domésticos. Todos laboran con baja dotación de capital, y en ocasiones utilizan capital obsoleto, depreciado y desechado por el sector moderno, razón por la cual su productividad es baja. Lo que motiva a los empresarios a participar en este sector es la baja rentabilidad de sus empresas, la cual no permite ab-

1 En Lewis, como en todo economista de la vertiente neoclásica, la decisión de emigrar y cambiar de actividad es la de un actor libre y perfectamente informado. En la versión estructuralista del dualismo, es libre, pero las opciones son restringidas por la falta de oportunidades. En ninguna de las dos versiones hay impedimentos legales a la movilidad. 
sorber los costos derivados de la normatividad laboral y otros costos de la formalidad, ni invertir. La mayoría de los empresarios en la informalidad cubren, a lo sumo, el costo de oportunidad del empleo formal. En momentos de crisis, o por retiro prematuro o a tiempo, muchos trabajadores con experiencia previa en el sector formal, en donde adquirieron entrenamiento y ahorros, apenas logran establecerse como empresarios informales por cuenta propia. Otros autores enfatizan los costos de permanecer en la informalidad, como son las limitaciones de crédito y de acceso a los programas de fomento y promoción, o la mayor exposición a la extorsión y la corrupción. El balance en estos estudios no indica que siempre los costos de permanecer en la informalidad sean inferiores a los ahorros que de ésta se puedan obtener (Neil McCulloch et al., 2010; Gutierrez-Romero, 2010).

\subsection{La informalidad y el dualismo según el modelo de Lewis $^{2}$}

Arthur Lewis desarrolló un modelo de crecimiento económico para los países en desarrollo, a partir de las características de su acumulación de capital. Su modelo constituye una alternativa al de Solow-Swan, ${ }^{3}$ pues abandona el presupuesto neoclásico de oferta de trabajo fija y la considera perfectamente elástica, sin bien conserva todos los demás presupuestos. En su trabajo "Desarrollo con oferta ilimitada de trabajo", Lewis sugiere que en los países en desarrollo coexisten un sector atrasado, no moderno, no capitalista, integrado por propietarios, autoempleados y trabajadores domésticos, quienes negocian un salario (C. Kirkpatrick y A. Barrientos, 2004: 7), y un sector moderno y urbano, con salarios rígidos. En el sector moderno, la productividad, las utilidades y las inversiones crecen $\mathrm{y}$, en este proceso, absorben trabajo del sector no moderno, de subsistencia, cuyos excedentes laborales garantizan, durante periodos prolongados, salarios constantes en el sector moderno. Esto es así porque la oferta de mano de obra al sector moderno supera su demanda. En estas condiciones, no se verifican rendimientos decrecientes del capital y se expande la participación, en el ingreso nacional, de las retribuciones al capital del sector moderno. Parte de las crecientes utilidades del sector moderno se reinvierten

2 Las ideas que aparecen en esta sección surgen de W. A. Lewis, "Economic Development with Unlimited Supplies of Labour", en Theodore Morgan (ed.), Readings in economic development, Belmont, Wadsworth, 1963, y W. A. Lewis, 1958. Esta sección también recoge elementos desarrollados José Romero (2000) y por José Romero y Óscar Fernández (2002). 
productivamente y aseguran su crecimiento permanente. Por lo tanto, el empleo informal está constituido por la oferta de trabajo que no logra incorporarse al sector formal, dadas las condiciones del mercado y las utilidades invertibles eficientemente en el sector formal. Para Lewis, este residuo sería temporal y acabaría por ser absorbido plenamente por la economía formal. El modelo de Lewis se centra en el producto medio del trabajo en el sector rural, y propone que hay emigración cuando se percibe que en el sector moderno puede obtenerse un salario superior al ingreso rural. Sin embargo, como lo sugiere el propio Lewis (1979), no toda la nueva oferta laboral se integra necesariamente al sector moderno. En efecto, el emigrante rural enfrenta tres opciones: empleo formal urbano, desempleo o empleo informal en las ciudades. En 1979, Lewis, aclaró y precisó su concepto de dualismo, el cual estaría integrado por "dos sectores que son 'el capitalista y el de subsistencia', no el industrial y el agrícola, no el urbano y el rural. Los urbanos pobres, los sirvientes domésticos, los pequeños comerciantes, los pequeños productores y los trabajadores en casa, fueron específicamente señalados como los grupos que mantienen la oferta abundante de mano de obra para el sector moderno", C. Kirkpatrick y A. Barrientos (2004: 7).

El desplazamiento de la mano de obra desde el sector no capitalista o atrasado al sector moderno o capitalista, avanza hasta donde la economía alcanza el punto de inflexión, en el cual, y durante un periodo suficientemente largo, la tasa de reubicación de la mano de obra supera el crecimiento de la población, acabando con el dualismo de la economía y en la transformación de ésta en una economía totalmente moderna y comercial (Ranis, 2004). En este proceso de cambio, según el modelo de Lewis, los ingresos reales suben cuando una economía pasa de la primera etapa de desarrollo clásico, de abundancia de mano de obra, a la segunda etapa, la de desarrollo neoclásico, de escasez de mano de obra y ascenso en el ingreso total de las remuneraciones al trabajo. Antes de llegar a esta etapa, se puede decir que los beneficios del crecimiento se realizan gracias a la absorción de los excedentes de mano de obra y no al crecimiento de los ingresos (Knight, 2007). ${ }^{4}$ Nuestro supuesto es que la economía mexicana se encuentra aún en la etapa de desarrollo clásico de abundancia de mano de obra previa al punto de inflexión lewisiano. En efecto, la razón de la productividad de las manufacturas a la agropecuaria se elevó de 5.4 en 1980 a 6.4 en 2010, pese al descenso del empleo agrícola en el total. Una trayectoria similar se registra para el ingreso medio y las remuneraciones medias (A. Puyana, 2011, ILO).

4 En Puyana y Romero, 2010, se analiza en detalle el modelo de Lewis, se elabora su formulación econométrica y se aplica al estudio del crecimiento mexicano entre 1940 y 2008. 


\section{La evolución del empleo informal en México, desde la creación del Seguro Social}

\subsection{Sobre el estudio de la informalidad en México}

La literatura sobre el sector informal en México es amplia y sofisticada; se centra en su dimensión y en sus características, y explica las razones de su expansión o supervivencia, experimentadas en las últimas dos décadas. Buena parte de los trabajos se vincula a la versión institucionalista, ya sea desde la perspectiva romántica o la parasitaria, ${ }^{5}$ y relativamente pocos se ubican en la propuesta estructuralista (Puyana et al., 2011). En términos sintéticos, la mayoría de los trabajos económicos sobre la informalidad en México, centran el análisis en las características y motivaciones de los individuos, y constatan que el grueso de la fuerza laboral mexicana está vinculado al sector informal, con todos los efectos que ello implica en términos de productividad e ingreso. Aceptan como informalidad la no afiliación a ningún sistema de seguridad social, y analizan -como elementos que sugieren la probabilidad de que un trabajador se vincule y permanezca en uno u otro sector - las características de los empleados informales con variables tales como el nivel educativo, el ingreso laboral, la edad, el género, el estado civil, la movilidad y, en algunos casos, la región geográfica. Se concluye que la educación y la edad son los elementos que más explican la decisión de optar por la informalidad. En este punto confluyen G. López-Acevedo y A. Salinas (2000). Según Rodríguez-Oreggia (2007), las empresas privilegian la juventud y prefieren el entrenamiento y el aprendizaje en el puesto de trabajo a la experiencia adquirida en otros empleos. El mismo Rodríguez-Orregia (2006), en un ensayo que aplica un modelo probabilístico, sugiere que la contingencia de pertenecer al sector informal es menor cuanto mayores sean la edad y el nivel educativo, y constata que el efecto más importante de la educación se da al pasar de la primaria a la secundaria, y no a los niveles superiores. Garro et al. (2005) estiman, asumiendo determinado crecimiento de la demanda laboral total y calculando la elasticidad de la demanda de trabajo respecto al costo de la seguridad social, que se podrían generar unos 300 mil puestos de trabajo con seguridad social si se reduce, en un punto, la tasa de contribución

5 Entre los trabajos más recientes sobre la informalidad en México, se encuentran: RodríguezOreggia (2006 y 2007), Garro et. al. (2005), Gerardo Esquivel y Juan Luis Ordaz Díaz (CEPAL, 2009), S. Levy (2007 y 2009); los de investigadores del Banco Mundial (Banco Mundial, 2004a , y Banco Mundial, 2004b), y W. F. Maloney (1999), Osorio et al. (1995) y M. V. Fazio (2010). 
del afiliado. Esquivel y Ordaz Díaz (2009) exploran si hay integración del mercado laboral informal y el formal, y si, como lo sugieren Levy (2007 y 2009) y Malony (1999 y 2004), los programas de asistencia social, aplicados por sucesivos gobiernos mexicanos, elevan la informalidad y retardan el crecimiento. La conclusión más importante de los ejercicios econométricos de este estudio, es que "los resultados basados en la técnica del propensity score matching muestran... que existe un premio salarial al trabajo en el sector formal de la economía, por lo que los mercados de trabajo en México no parecen estar integrados, como lo supone la hipótesis en cuestión [la de los citados trabajos de Levy y Malony]. Por lo tanto, la evidencia obtenida por Esquivel et al. (2009) permite afirmar que en México los aumentos recientes en los programas sociales no son una causa de la informalidad" (Esquivel et al., op. cit., pág. 35). En el mismo sentido concluye, para México, Gutiérrez-Romero, quien prueba que a mayor desigualdad en la riqueza más desequilibradas las oportunidades para convertirse en empresario formal, pues los empresarios formales más grandes logran, pagando mayores salarios (los premios salariales en Esquivel et al.), sacar del mercado o expulsar hacia la informalidad, a las empresas menores, lo cual eleva el poder de mercado de los primeros. Neil McCulloch et al. (2010) sustentan hallazgos similares para el caso indonesio.

\subsection{La trayectoria del empleo informal desde la creación del Seguro Social}

Es notable la evolución del mercado laboral mexicano en las más de seis décadas transcurridas desde 1945, cuando se creó el Seguro Social. Esta trayectoria ha estado marcada por varias crisis de diferentes intensidades, las cuales han afectado la estructura de la economía y la participación de los factores productivos. La transformación estructural más importante que estos sucesos han ocasionado comprende, por una parte, la contracción de la agricultura y el estancamiento de las manufacturas en el PIB y el empleo totales - sucesos concomitantes con el avance del sector servicios - , y por la otra, el crecimiento del coeficiente de apertura de la economía ${ }^{6}$ (A. Puyana y J. Romero, 2009; Escaith, 2006). Durante este periplo, la informalidad, definida como el empleo sin protección social (no registrado en el IMSS ni en el ISSSTE), cayó de 96\% en 1945, a cerca de

6 El coeficiente de apertura de la economía se mide como: (importaciones más exportaciones/ $\mathrm{PIB})^{*} 100$. Esta medida señala el grado en el cual la producción mexicana compite en los mercados interno y externo. 


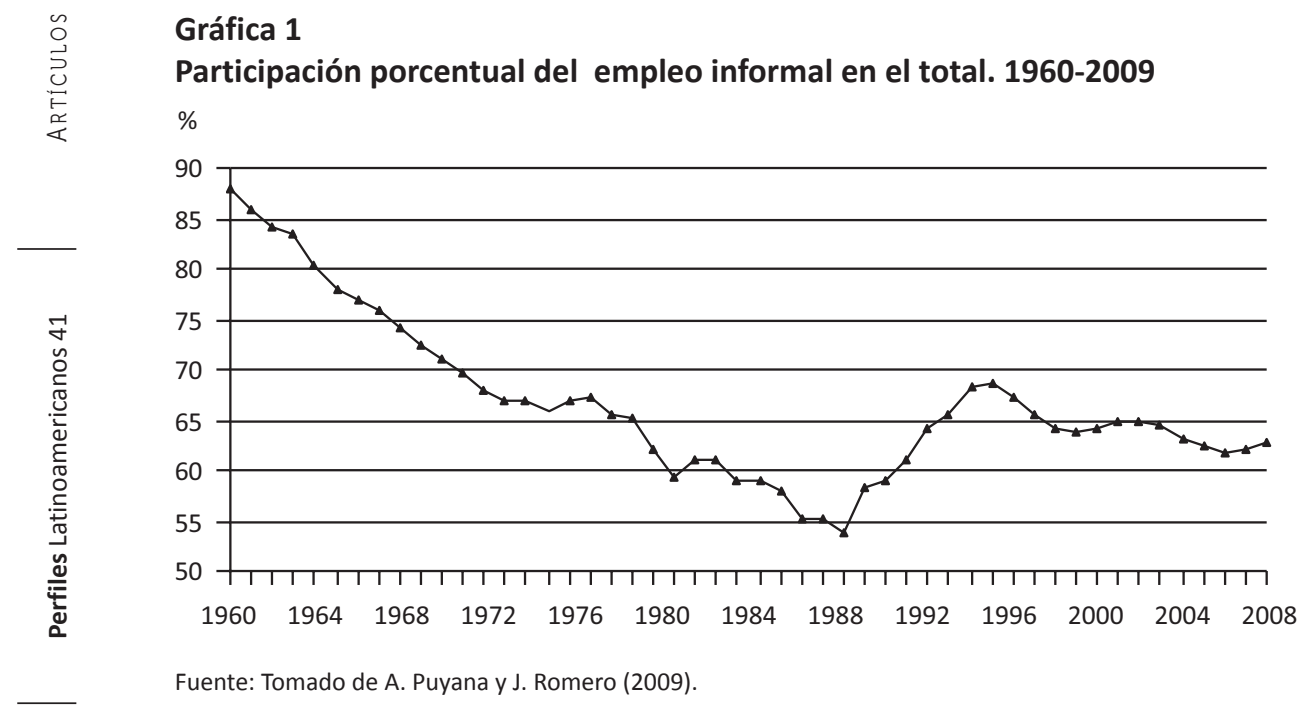

$88 \%$ en 1960, cuando entraban en plena vigencia el modelo sustitutivo, el desarrollo estabilizador y la urbanización. A partir de 1960 y hasta 1983, es evidente el avance del empleo formal en el total. Después de la crisis de la deuda, el crecimiento relativo del empleo informal continuó, pero a un ritmo más lento, y con el estallido de la crisis en 2009, la informalidad se incrementó a tal punto que llegó a alcanzar una proporción similar a la registrada en 1980 (véase gráfico 1). Hernández Laos sugiere que, con la inclusión del sector agropecuario, el empleo informal ascendió a 70\% del total, proporción similar a la encontrada por Puyana y Romero (2009), N. Cervantes et al. (2006) y Fazzio (2010), que lo ubican en $65 \%$. Se podría sugerir entonces que, a partir de 1982-86, se detuvo el crecimiento del empleo cubierto por alguna modalidad de seguridad social. Esta tendencia coincide también con la aceleración del retroceso del sector agropecuario como fuente de empleo e ingresos, y con el cambio en la trayectoria de la absorción de empleo por el sector manufacturero (Puyana y Romero, 2012). Desde las reformas, las inversiones requeridas para generar una plaza de trabajo en las manufacturas ascendieron considerablemente, a la vez que se desaceleraban las inversiones por trabajador (Puyana et al., 2011).

Al aplicar los supuestos del modelo de desarrollo de Lewis (1958 y 1979), se podría proponer que la desigualdad en condiciones laborales y de productividad, que separa al campo mexicano de las urbes o de las ciudades intermedias, engrosa continuamente la oferta laboral urbana y presiona a 
la baja los salarios urbanos reales bajos, como se verifica en Puyana et al., 2012. Cabe recordar que el descenso del empleo agrícola en el total, fue un objetivo implícito de las reformas de las políticas hacia el sector, como preparación para la entrada en el GATT y a los compromisos en el TLCAN. De 1980 a 2010, el empleo en el sector agropecuario, como porcentaje del total, descendió de 23 a 13\%, mientras que su peso en el PIB bajó de 9 a $3.7 \%$, lo que corrobora su menor productividad y la permanencia tanto de excedentes laborales como del dualismo.

\section{La informalidad urbana en México desde 1994}

A continuación presentamos la estructura del empleo urbano en cuanto a su distribución en formal e informal, según el tamaño de las unidades productivas, ateniéndonos a los datos publicados por el INEGI en Censos económicos y encuestas. Resultados definitivos, de los años 1994 y 2009. En éstos aparecen siete variables económicas para caracterizar las unidades económicas. INEGI clasifica como informales las unidades productivas de menos de 15 trabajadores, en las manufacturas, y de menos de 10 trabajadores en el sector de los servicios. La discriminación de los establecimientos censados en estas dos ramas económicas, permite ilustrar el papel de los servicios en cuanto receptáculo tanto del empleo desplazado del campo mexicano como de la oferta de trabajo no incorporada a la formalidad, y, de alguna manera, como reproductor del dualismo económico, definido, en los términos de Lewis, como los grupos que mantienen oferta abundante de mano de obra para el sector moderno o capitalista.

De los cerca de un millón y medio de todos los establecimientos industriales y de servicios censados en 2009, 95\%, es decir, alrededor de un millón y medio de unidades económicas, eran informales, en los términos señalados arriba, y generaron ese año cerca de diez millones doscientos mil empleos. El cuadro 2 presenta, en la primera columna, el número total de establecimientos censados y algunas de las variables suministradas en el censo. En la segunda columna aparecen las cifras correspondientes al sector informal total. La tercera columna contiene la participación porcentual del sector informal en el total de establecimientos censados; la cuarta, la quinta y la sexta presentan las tasas de crecimiento respectivas. Tanto el número de unidades productivas como el empleo generado en el sector informal, crecieron más que en el total y más que el sector formal. Las remuneraciones totales en el sector informal registraron un crecimiento de 0.7, un tanto superior al resto de establecimientos. 


\begin{tabular}{|c|c|c|c|c|c|c|c|c|c|}
\hline \multirow[t]{3}{*}{ 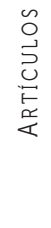 } & \multicolumn{9}{|c|}{$\begin{array}{l}\text { Cuadro } 1 \\
\text { Algunos indicadores de la composición del total de establecimientos } \\
\text { censados. 1994-2009 }\end{array}$} \\
\hline & \multirow{2}{*}{$\begin{array}{l}\text { Indicadores } \\
\text { económicos }\end{array}$} & \multirow[b]{2}{*}{ Año } & \multicolumn{3}{|c|}{ Unidades productivas } & \multirow[b]{2}{*}{ Particip. \% } & \multicolumn{3}{|c|}{ T. Crecimiento } \\
\hline & & & Total & Informal & Formal & & Total & Informal & Formal \\
\hline \multirow{10}{*}{ 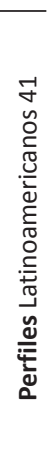 } & \multirow[t]{2}{*}{ Unidades económicas* } & 1994 & 1006 & 960 & 45 & 95.48 & \multirow[t]{2}{*}{1.15} & \multirow[t]{2}{*}{1.16} & \multirow[t]{2}{*}{1.10} \\
\hline & & 2009 & 1498 & 1432 & 67 & 95.56 & & & \\
\hline & \multirow[t]{2}{*}{ Personal ocupado* } & 1994 & 6451 & 2362 & 4089 & 36.62 & \multirow[t]{2}{*}{1.33} & \multirow[t]{2}{*}{1.61} & \multirow[t]{2}{*}{1.15} \\
\hline & & 2009 & 10198 & 4117 & 6081 & 40.37 & & & \\
\hline & \multirow[t]{2}{*}{ FBCF** } & 1994 & 132.95 & 28.03 & 105 & 21.08 & \multirow[t]{2}{*}{0.76} & \multirow[t]{2}{*}{-3.83} & \multirow[t]{2}{*}{1.32} \\
\hline & & 2009 & 172.83 & 7.46 & 165 & 4.32 & & & \\
\hline & \multirow[t]{2}{*}{ V. Agregado bruto** } & 1994 & 1105.11 & 206.25 & 899 & 18.66 & \multirow[t]{2}{*}{1.27} & \multirow[t]{2}{*}{-0.49} & \multirow[t]{2}{*}{1.56} \\
\hline & & 2009 & 1713.41 & 174.30 & 1539 & 10.17 & & & \\
\hline & \multirow{2}{*}{$\begin{array}{l}\text { Remuneraciones } \\
\text { totales** }\end{array}$} & 1994 & 439.17 & 44.72 & 394 & 10.18 & \multirow[t]{2}{*}{0.37} & \multirow[t]{2}{*}{0.75} & \multirow[t]{2}{*}{0.32} \\
\hline & & 2009 & 498.56 & 57.89 & 441 & 11.61 & & & \\
\hline & \multirow[t]{2}{*}{ Tamaño promedio } & 1994 & 6.41 & 2.46 & 89.89 & & \multirow[t]{2}{*}{0.17} & \multirow[t]{2}{*}{0.45} & \multirow[t]{2}{*}{0.05} \\
\hline & & 2009 & 6.81 & 2.88 & 91.36 & & & & \\
\hline
\end{tabular}

*Miles. ** Miles de millones de pesos de 2002

Fuente: Cálculos propios basados en INEGI: Censos económicos. Resultados definitivos, 1994-2009.

Mientras que en 2009, los establecimientos informales concentraron 95\% del total de unidades y $40.37 \%$ del empleo, con tasas de crecimiento superiores, entre 1994 y 2009, al total de las empresas, su peso disminuye a medida que se avanza hacia las variables que indican productividad y dotación de capital. Por ejemplo, los establecimientos informales sólo concentraron $4.32 \%$ de la formación bruta de capital fijo (FBCF) y $10.17 \%$ del valor agregado. Estas brechas muestran un dualismo que se intensifica, como lo indican las tasas de crecimiento negativas en las variables que valoran la trayectoria económica de las empresas. De las variables presentadas, sólo la participación del sector informal creció relativamente poco en número de unidades y un tanto más en empleo y tamaño promedio, y decreció en FBCF y valor agregado. En términos "lewisianos", todavía no ha concluido el desplazamiento de mano de obra desde el sector informal o atrasado al formal o moderno, pues el primero muestra tasas de crecimiento mayores que el segundo. ¿O presenciamos la trayectoria inversa: el movimiento de trabajo del segundo al primero, conforme se agranda la brecha en formación de capital? A simple vista, podemos sugerir que no se ha producido aún el tránsito hacia la segunda etapa del crecimiento propuesta por Lewis, pues el número de establecimientos y trabajadores vinculados al sector infor- 
mal, crece a ritmo mayor que el total y que el sector formal. Hay otros factores determinantes cuya importancia debe ser reconocida y considerada, aunque no se analicen: factores como el cambio tecnológico y la especialización productiva y en el comercio internacional. Éstos y otros elementos omitidos, como el acervo de activos, restringen los alcances de este trabajo.

\section{La composición sectorial de la informalidad}

Una vez establecido el peso de los establecimientos no formales en el total de unidades productivas, y luego de considerar su evolución durante 1994-2009, periodo que abarca la consolidación de las reformas estructurales y el ajuste de la economía a éstas y a las relaciones económicas y comerciales que se estructuraron con el TLCAN, procederemos a analizar la concentración de los establecimientos no formales en el sector servicios y en las manufacturas. Según INEGI, en 2009 las manufacturas concentraron cerca de $29 \%$ del empleo y de las unidades productivas informales, proporción que supera la participación de las manufacturas en el empleo y el PIB totales, que lindan $10 \%$ y $20 \%$, respectivamente, como se muestra en Puyana 2011; y tiene proporciones algo menores en lo relativo a la formación bruta de capital fijo y el valor agregado. Del cuadro 2 se desprende el mayor peso del sector servicios en el empleo informal total y en las unidades productivas de menos de 15 trabajadores; a este mayor peso, que refleja la estructura de la economía total, lo ratifican algunas conclusiones propias (Puyana y Romero, 2009 y 2010; Puyana, 2011) y de varios autores (Palma, 2010 y 2009; Scaith, 2007) sobre la fractura estructural del PIB nacional, constatada en el prematuro retroceso de las manufacturas y de la agricultura como fuente de empleo y PIB, y por la prematura terciarización de la economía, resultante entre otros, de la revaluación de la tasa real de cambio, la abundancia de recursos externos provenientes de las exportaciones de petróleo, las remesas y los flujos de financieros externos, amén de la forma en que se liberalizó la economía y se sellaron los acuerdos en el TLCAN.

La informalidad en manufacturas y servicios, según los censos de establecimientos de INEGI, 1994-2009, es resistente y se ha reproducido, como se colige de las tasas de crecimiento anual promedio, del número de establecimientos informales en manufacturas $(1.54 \%)$ y en servicios $(1.01 \%), y$ del volumen del empleo generado en ambos sectores (1.61\%). La trayectoria de estas variables contrasta con la evolución de la formación bruta de capital fijo $(-4.12 \%)$ o del valor agregado $(-2.37 \%)$, y sugiere que se amplía 
la brecha entre la informalidad y las empresas medianas y grandes, como se verá más adelante.

\section{El dualismo en el sector manufacturero mexicano, 1994-2009}

Aunque, según los datos del INEGI, el peso de la informalidad manufacturera es menor (28.8\% de los establecimientos, y 29.11\% del empleo) que en el sector servicios, su importancia deriva de la centralidad de las manufacturas en el modelo exportador mexicano, lo que justifica considerar su estructura según el tamaño de las unidades productivas y cómo se distribuyen entre éstas la inversión, la productividad y los ingresos. Esta distribución es la base del dualismo sectorial y nos da una idea de las dificultades que encuentra la integración de las cadenas productivas.

Las manufacturas han sido consideradas el factor clave del desarrollo económico, por su capacidad de impulsar el crecimiento de la productividad de toda la economía, y porque sus exportaciones son motor del crecimiento al estimular el avance científico y tecnológico, propio o por apropiación o adaptación, según lo expusiera Kaldor en sus famosas tres leyes (Kaldor, 1968 y 1975; Thirlwall, 1983; Puyana y Romero, 2009). Como podemos constatarlo a grandes rasgos, en los censos de 2009 se contaron 413 mil unidades productivas manufactureras de hasta 15 operarios, las cuales dieron empleo a 1 millón 198 mil trabajadores (la Enamin 2008 da para manufacturas 463 establecimientos y 1.2 millones de trabajadores), de lo cual se desprende, para 2009, un tamaño promedio de 2.90 trabajadores por unidad (un ligero aumento con relación a 1994, cuando el tamaño promedio fue de 2.87 operarios).

En nuestra opinión, si el sector moderno manufacturero hubiera sido el motor de la transformación de la economía, su crecimiento y las inversiones que éste realizara tendrían como efecto acelerar y completar la reasignación de mano de obra desde el sector informal al elevar la demanda de trabajo, con lo cual crecerían la dotación de capital, la productividad y los salarios reales de todo el sector. México estaría en la fase de crecimiento denominado neoclásico, es decir, de escasez de mano de obra y ascenso en el ingreso total de las remuneraciones al trabajo (Knight, 2007). ${ }^{7}$ Los datos que se analizan a continuación sugieren que ése no es el caso y que México aún no ha terminado la primera etapa de

7 En Puyana y Romero, 2010, se analiza en detalle el modelo de Lewis, se elabora su formulación econométrica y se aplica al estudio del crecimiento mexicano entre 1940 y 2008. 
Cuadro 2

Algunos indicadores de la relación entre las unidades productivas formales e informales del sector manufacturero mexicano 1994-2009. En porcentajes

\begin{tabular}{|c|c|c|c|c|c|c|c|c|c|c|}
\hline \multirow[b]{2}{*}{ Personal } & \multicolumn{2}{|c|}{$\begin{array}{l}\text { Unidades } \\
\text { económicas }\end{array}$} & \multicolumn{2}{|c|}{$\begin{array}{l}\text { Personal } \\
\text { ocupado }\end{array}$} & \multicolumn{2}{|c|}{$F B K F^{*}$} & \multicolumn{2}{|c|}{$\begin{array}{l}\text { Valor agregado } \\
\text { censal bruto* }\end{array}$} & \multicolumn{2}{|c|}{ Remuneraciones* } \\
\hline & 1994 & 2009 & 1994 & 2009 & 1994 & 2009 & 1994 & 2009 & 1994 & 2009 \\
\hline 0 a 5 & 81.57 & 84.19 & 13.84 & 17.47 & 2.87 & 1.15 & 5.95 & 1.78 & 1.69 & 2.26 \\
\hline 6 a 10 & 7.29 & 8.34 & 4.45 & 5.72 & 1.35 & 0.62 & 2.17 & 1.06 & 1.86 & 2.04 \\
\hline 11 a 15 & 2.73 & 2.13 & 2.85 & 2.52 & 1.02 & 0.45 & 1.73 & 0.75 & 1.60 & 1.33 \\
\hline 0 a 15 & 91.59 & 94.65 & 21.14 & 25.71 & 5.24 & 2.23 & 9.85 & 3.59 & 5.16 & 5.63 \\
\hline 16 a 50 & 4.80 & 2.98 & 10.83 & 7.50 & 5.46 & 2.84 & 7.66 & 3.55 & 8.01 & 5.25 \\
\hline 51 a 250 & 2.75 & 1.63 & 24.36 & 17.12 & 27.84 & 19.12 & 20.36 & 17.51 & 25.42 & 17.78 \\
\hline 251 a 1000 & 0.76 & 0.61 & 28.53 & 27.73 & 44.45 & 45.01 & 35.93 & 39.59 & 37.78 & 35.55 \\
\hline 1001 y más & 0.10 & 0.13 & 15.14 & 21.94 & 17.00 & 30.80 & 26.19 & 35.76 & 23.63 & 35.79 \\
\hline Total & 100.00 & 100.00 & 100.00 & 100.00 & 100.00 & 100.00 & 100.00 & 100.00 & 100.00 & 100.00 \\
\hline
\end{tabular}

*Miles de Pesos de 2002.

Fuente: INEGI: Censos económicos. Resultados definitivos, 1994 y 2009.

crecimiento con abundancia de mano de obra y remuneraciones reales constantes o a la baja.

\subsection{El dualismo en las manufacturas mexicanas}

En 2009, el universo de las unidades productivas manufactureras, conformado por los establecimiento de cero a 15 trabajadores, estuvo integrado por 413000 unidades que concentraron $94.7 \%$ del total de las unidades productivas, y $25.7 \%$ del personal ocupado en el sector, en una tendencia al alza en las dos variables. En este conjunto no homogéneo predominó el peso de las unidades de entre cero y cinco trabajadores, las cuales respondieron por $84.19 \%$ de los establecimientos y concentraron, ese mismo año, 814000 trabajadores, o sea, 17.47\% del total de empleados manufactureros (véase el cuadro 3). En este cuadro deseamos resaltar el peso del sector informal, la brecha que lo separa de las grandes y medianas empresas, y las variables que en nuestra opinión marcan la diferencia y la perpetúan.

Esperaríamos, de acuerdo con Lewis, que en la medida en que crezca la economía, se desarrolle su sector manufacturero y, con éste, el sector moderno de la economía, gracias a la reinversión de utilidades, a tal pun- 
to que se absorban los excedentes de mano de obra y nivelen la productividad y las remuneraciones. Los resultados obtenidos son sorprendentes, como se detalla en el cuadro 3, que presenta el total de los establecimientos manufactureros de toda la industria clasificados por tamaño de empresas.

Lo más problemático es el abismo abierto entre el peso del número de establecimiento y empleados, y la formación bruta de capital y valor agregado, abismo que resulta en una participación en las remuneraciones igualmente dispar. Como lo anota un dictaminador anónimo, es necesario considerar que la FBK tiene amplias variaciones según el ciclo y las características de las actividades, además de otros factores diferentes de los que determinan las oscilaciones del valor agregado. Los establecimientos de más de mil trabajadores, concentraron 30.8\% de la FBCF, y 35.8\% del valor agregado y de remuneraciones, cuando sólo respondían por $22 \%$ de los trabajadores, en consonancia con su característica de tener mayor dotación de capital por trabajador $\mathrm{K} / \mathrm{L}$, lo que es esperable. Un dato importante revelado por el cuadro 4, es que las empresas consideradas pequeñas y medianas, las que emplean entre 16 y 250 trabajadores, han perdido peso en todas las variables señaladas, especialmente en FBCF y valor agregado, lo que sugiere un retroceso en la capacidad productiva y un predominio de las empresas mayores.

Esta cifras señalan las dificultades del sector manufacturero para integrarse en uno solo en eficientes relaciones de cooperación industrial; es decir: en relaciones donde las empresas informales estén provistas de similar tecnología y de niveles análogos de productividad que las grandes y medianas empresas, y puedan entrar con éstas en relaciones de proveeduría de partes y componentes y ser partícipes del progreso y de las exportaciones. Dicho en términos contemporáneos: las cifras mencionadas indican las dificultades del sector para integrar las cadenas productivas.

Las anteriores sugerencias se pueden analizar también a partir de las tasas de crecimiento anuales promedio de las variables señaladas anteriormente, mismas que se presentan en la tabla 5. Entre 1994 y 2009, el empleo en las unidades informales creció más aceleradamente que el número de éstas, lo que resultó en el muy pequeño incremento de su tamaño promedio. Los establecimientos de menos de 15 empleados registraron crecimiento solamente en el número de unidades y empleados y en las remuneraciones, y decrecimiento en todas las demás variables. Si bien el empleo creció más en las unidades de más de mil trabajadores, las cuales se revelan como las de mayor dinamismo, ello no ha sido suficiente para absorber volúmenes significativos de empleo, ya que su participación en el número de trabaja- 
Cuadro 3

Tasas de crecimiento de algunos indicadores del sector manufacturero mexicano. 1994-2009

\begin{tabular}{cccccc}
\hline Personal & Unidades & Empleo & FBCF & Valor agregado & Remuneraciones totales \\
\hline 0 a 5 & 1.53 & 1.72 & -2.55 & -1.93 & 1.17 \\
6 a 10 & 1.83 & 1.77 & -2.12 & -0.51 & 0.60 \\
11 a 15 & 0.72 & 0.69 & -2.25 & -0.88 & -0.21 \\
0 a 15 & 1.54 & 1.61 & -2.37 & -1.36 & 0.59 \\
16 a 50 & 0.07 & -0.02 & -1.79 & -0.67 & -0.89 \\
51 a 250 & -0.07 & 0.03 & -0.99 & 1.12 & -0.70 \\
251 a 1000 & 0.79 & 0.97 & 0.13 & 1.84 & 0.16 \\
1001 y más & 2.07 & 2.12 & 1.82 & 2.46 & 1.54 \\
\hline Total & 1.44 & 1.05 & 0.10 & 1.56 & 0.34 \\
\hline
\end{tabular}

Fuente: INEGI: Censos económicos. Resultados definitivos, 1994-2009.

dores se redujo entre 2004 y 2009. Estas empresas registraron las mayores tasas de crecimiento de la FBCF, las cuales fueron menores que las del empleo. Se podría concluir, junto con Roxana Gutierrez-Romero (2010), que estas unidades compiten con las menores y constriñen su crecimiento, por la falta de oportunidades para adquirir crédito y tecnología. La formación bruta de capital fijo ha descendido para los seis primeros tamaños de empresas, salvo para las empresas de más de 251 mil trabajadores (las filas antepenúltima y penúltima del cuadro 4). En el sector informal se registró el mayor descenso en la $\mathrm{FBCF}$, al tiempo que crecieron el número de unidades productivas y el de trabajadores (véase el cuadro 4).

Un factor preocupante es la trayectoria de las unidades productivas pequeñas (entre 16 y 50 empleos) y de tamaño medio (entre 50 y 250 empleos), ya que este universo puede ser considerado el eslabón con la gran empresa y el que haría posible la integración de las cadenas productivas. El peso de las unidades pequeñas se ha reducido en todas las variables, salvo en su número, y se acercan a las de menos de 15 trabajadores.

Lo que sorprende, y exige remedios, es el crecimiento negativo de la formación bruta de capital fijo en las empresas de todo rango, desde las de menos de cinco hasta las de 250 trabajadores; es decir: en 99.2\% de todas las unidades productivas, las cuales albergan 50.3\% de los trabajadores, se registró un descenso en la FBCF. Esta caída fue muy elevada en las empresas de entre 16 a 50 trabajadores, seguidas por las unidades de menos de 10 operarios. Las únicas empresas que elevaron la formación bruta de capital fijo, fueron las de de 251 y más, pero especialmente las de más de 


\begin{tabular}{|c|c|c|c|c|c|c|c|c|c|}
\hline \multirow[t]{2}{*}{ 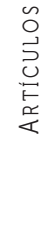 } & \multicolumn{9}{|c|}{$\begin{array}{l}\text { Valores por trabajador en las empresas del sector manufacturero. } \\
\text { 1994-2009. Miles de pesos de } 2002\end{array}$} \\
\hline & \multirow[b]{2}{*}{ Personal } & \multicolumn{2}{|c|}{ Personal/unidades } & \multicolumn{2}{|c|}{ FBKF } & \multicolumn{2}{|c|}{$\begin{array}{l}\text { Valor agregado } \\
\text { censal bruto }\end{array}$} & \multicolumn{2}{|c|}{ Remuneraciones } \\
\hline \multirow{10}{*}{ 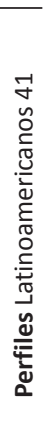 } & & 1994 & 2009 & 1994 & 2009 & 1994 & 2009 & 1994 & 2009 \\
\hline & 0 a 5 & 2.07 & 2.21 & 4.34 & 0.99 & 88.85 & 25.14 & 9.58 & 7.91 \\
\hline & 6 a 10 & 7.47 & 7.32 & 6.31 & 1.64 & 100.89 & 45.90 & 32.68 & 21.83 \\
\hline & 11 a 15 & 12.74 & 12.62 & 7.50 & 2.71 & 125.60 & 72.83 & 44.08 & 32.30 \\
\hline & 0 a 15 & 2.82 & 2.90 & 5.18 & 1.31 & 96.34 & 34.43 & 19.09 & 13.40 \\
\hline & 16 a 50 & 27.58 & 26.83 & 10.53 & 5.70 & 146.18 & 116.56 & 57.85 & 42.83 \\
\hline & 51 a 250 & 108.47 & 112.18 & 23.87 & 16.80 & 172.72 & 252.12 & 81.63 & 63.59 \\
\hline & 251 a 1000 & 460.12 & 488.15 & 32.54 & 24.42 & 260.22 & 351.81 & 103.61 & 78.47 \\
\hline & 1001 y más & 1806.39 & 1839.24 & 23.46 & 21.13 & 357.60 & 401.73 & 122.17 & 99.85 \\
\hline & Total & 12.23 & 10.67 & 20.89 & 15.05 & 206.66 & 246.46 & 78.24 & 61.21 \\
\hline
\end{tabular}

Fuente: INEGI: Censos económicos. Resultados definitivos, 1994-2009.

mil trabajadores, con lo cual se incrementó la brecha en el sector manufacturero. Pero en ninguno de estos dos casos, la tasa de crecimiento de la FBCF superó ni la del número de trabajadores ni el de empresas, con lo cual descendió la dotación de capital por empresa y por trabajador. Esta evolución negativa de la formación bruta de capital fijo, sugiere un descenso generalizado de la capacidad productiva del sector manufacturero; no se preservó la dotación por trabajador, en la medida en que, para el conjunto de los establecimientos manufactureros, esta variable registró, entre 19942009, un aumento de $0.11 \%$ anual promedio, muy inferior al número de establecimientos $(1.55 \%)$ y de trabajadores $(1.12 \%)$. El descenso de la formación y dotación de capital por trabajador, que ya se había destacado en trabajos anteriores (Puyana et al., 2009 y 2010; Puyana, 2011) y se detalla en la sección siguiente, es preocupante, pues tuvo lugar a partir de la entrada en vigencia del TLCAN y cuando México puso en vigor todas las salvaguardias y garantías a la inversión privada extranjera y, siguiendo la teoría del crowding-out, había reducido drásticamente las inversiones públicas para fomentar la privada. La trayectoria de las inversiones no guarda correspondencia con el formidable incremento de las exportaciones de manufacturas, fenómeno que plantea interrogantes. La baja acumulación de capital en las manufacturas mexicanas, está asociada al avance de la maquila en todo el conjunto productivo, y corrobora lo sugerido en otros estudios sobre la falta de oportunidades reales de inversión (Puyana et al., 2010). 
Cuadro 5

Tasas de crecimiento. De los valores por trabajador en las empresas del sector manufacturero. 1994-2009

\begin{tabular}{cccccc}
\hline Personal & $\begin{array}{c}\text { Unidades } \\
\text { económicas }\end{array}$ & $\begin{array}{c}\text { Producción } \\
\text { bruta total }\end{array}$ & $\begin{array}{c}\text { Formación bruta } \\
\text { de capital fijo }\end{array}$ & $\begin{array}{c}\text { Valor agregado } \\
\text { censal bruto }\end{array}$ & Remuneraciones \\
\hline 0 a 5 & 0.19 & -3.63 & -4.27 & -3.66 & -0.55 \\
6 a 10 & -0.06 & -2.00 & -3.89 & -2.28 & -1.17 \\
11 a 15 & -0.03 & -1.13 & -2.95 & -1.58 & -0.90 \\
0 a 15 & 0.08 & -2.82 & -3.99 & -2.98 & -1.03 \\
16 a 50 & -0.08 & -0.06 & -1.78 & -0.66 & -0.87 \\
51 a 250 & 0.10 & 1.21 & -1.02 & 1.10 & -0.72 \\
251 a 1000 & 0.17 & 1.07 & -0.83 & 0.87 & -0.80 \\
1001 y más & 0.05 & 1.04 & -0.30 & 0.34 & -0.58 \\
\hline Total & -0.39 & 0.96 & -0.95 & 0.51 & -0.71 \\
\hline
\end{tabular}

Fuente: INEGI: Censos económicos. Resultados definitivos, 1994-2009.

4.2 El dualismo en las manufacturas a partir de indicadores de desempeño por trabajador

Las anteriores consideraciones sugieren la importancia de explorar cómo han evolucionado los valores por trabajador informal manufacturero, especialmente los relacionados con las inversiones y con la productividad media. En otros trabajos se ha enfatizado la pérdida tanto de la dinámica de la formación bruta de capital como de la proporción del PIB por trabajador, la cual está detrás de la débil dinámica de la productividad total de la economía (Puyana y Romero, 2009 y 2011) y de la baja absorción de trabajo por parte de los sectores transables y de las empresas formales, lo que conduce a sugerir que la economía mexicana ha padecido más por falta de oportunidades de inversión que por escasez de recursos de inversión (Puyana y Romero, 2011 y 2010).

Los valores por trabajador informal en manufacturas y su evolución, presentados en el cuadro 5, corroboran la sugerencia hecha anteriormente en el sentido de la agudización del dualismo en la economía mexicana.

Son evidentes las brechas que separan a $94 \%$ de los establecimientos manufactureros y a $25 \%$ de los trabajadores de estos valores, en las grandes unidades productivas (de más de mil operarios). Deseamos recalcar que las diferencias en formación bruta de capital fijo marcan, en cierta medida, la brecha en productividad. Al ser mayor la brecha en formación bruta de capital que en valor agregado por trabajador, se podría sugerir que los establecimientos informales trabajan más horas y con mayor intensidad 
que sus contrapartes de la gran empresa, ya que el valor agregado por trabajador o productividad laboral, está relacionado en alguna medida con la dotación de capital. El cuadro 5 presenta los valores por trabajador de las variables empleadas para describir las características de las empresas.

El cuadro 6, con las tasas de crecimiento de los valores por trabajador, permite corroborar la sugerencia hecha anteriormente en el sentido de la agudización del dualismo en la economía mexicana. Se registra el crecimiento, uno muy leve, del tamaño promedio de las empresas de menos de 15 trabajadores, y uno algo mayor en el número de éstas y en el empleo que generaron. En contraste, estas unidades productivas sufrieron caídas importantes en los valores por trabajador de: la formación bruta de capital fijo, el valor agregado y las remuneraciones. Según nuestro leal saber y entender, es en la carencia de capital, una falencia que afecta a toda la economía, donde radican el bajo rendimiento y la persistencia del dualismo productivo, no obstante que la $\mathrm{FBCF}$, al ser una variable de flujo, tiene variaciones según el ciclo económico. Sin embargo, al considerar un periodo relativamente largo, esa preocupación se reduce. Por otra parte, los ciclos pueden afectar a todas las empresas, y en el cuadro 6 se evidencia que el impacto fue mayor para las de menos de 15 trabajadores. En términos ideales, sería interesante explorar, por ejemplo, el acervo de los activos, para lo cual no encontramos información discriminada por tamaño de empresas. La Enamin se limita a registrar si los micronegocios disponen de local propio o arrendado, de vehículos con o sin motor, y algunos datos de gastos para compra de materias primas y de maquinaria, y para el mantenimiento o arreglos de ésta, lo cual no suministra ningún dato sobre el acervo de activos (INEGI, 2009). Así, entre 1994 y 2009, la distancia entre las grandes y las micro, pequeñas y medianas empresas, creció en vez de contraerse, a la vez que, en ese periodo, el PIB manufacturero se expandió a una tasa anual promedio del $2.31 \%$, y se consolidó la especialización de México en la exportación de manufacturas (Puyana, 2011).

\section{La trayectoria de la informalidad analizada a partir de índices de concentración}

El crecimiento de la informalidad y el dualismo en las manufacturas mexicanas, tema que hemos abordado en las secciones anteriores, se aprecia con mayor claridad a partir del Índice Herfindahl, una medida inicialmente aplicada a los estudios de mercado para calcular la concentración y el poder de mercado ejercido por cada empresa o grupo de empresas. Últimamente, 
sin embargo, se ha extendido su aplicación al estudio de universos muy diferentes, y al examen de la distribución y los cambios de los pesos relativos de las variables que los caracterizan. Analizaremos el grado de concentración de las diversas categorías de empresas, según su tamaño y el peso de cada una de las variables analizadas. La expresión numérica del índice Herfindahl: es:

$$
H=\sum_{i=1}^{N} S_{i}^{2}
$$

donde $s_{i}$ es la participación del tamaño de empresa $i$ en el total de empresas. El índice normalizado se expresa como:

$$
H^{*}=\frac{H-(1 / N)}{1-(1 / N)}
$$

Donde $N$ es el número de empresas. El valor del índice oscila entre 0 y 1 mayor la concentración y viceversa superior su valor.

Para el cálculo del Herfindahl, se tomaron en cuenta, en cada una de las ocho ramas de la actividad manufacturera y para el total, seis categorías de empresas según su tamaño, definido por el número de trabajadores: a) 0 a 5; b) 6 a 10; c) 11 a 50; d) 51 a 250; e) 251 a 1000 y f) más de 1001 trabajadores.

Dado que el índice magnifica la participación del rango de tamaño de empresa $\left(S_{i}\right)$ en la variable que se estudia (la eleva al cuadrado), tendremos un elevado valor del índice de Herfindahl cuando cierto rango de tamaño de empresa concentra una elevada participación en la variable de interés. Por ejemplo, en el caso de las "unidades" tenemos un elevado número de empresas en el rango de empresas de 0-5, y el índice señala adecuadamente esta situación, tanto para el conjunto de las manufacturas como para las ramas individuales. Es alto en prácticamente todas las ramas, excepto en la rama 35 (sustancias químicas, productos derivados del petróleo y del carbón de hule y de plástico), donde la alta intensidad de capital no admite gran numero de empresas pequeñas. De la misma manera, en el caso del empleo dentro del rango de empresas de menor tamaño, éstas tienen menor participación en el empleo total, y esto se ve reflejado en un menor índice de Herfindahl. Cuando, debido a los requerimientos de capital de la rama, ésta no admite la existencia de gran cantidad de empresas pequeñas, el empleo se concentra en rangos de mayor tamaño, tal como ocurre en las 


\begin{tabular}{|c|c|c|c|c|c|c|c|c|c|c|c|}
\hline \multirow[t]{3}{*}{ 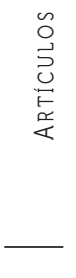 } & \multicolumn{11}{|c|}{$\begin{array}{l}\text { Cuadro } 6 \\
\text { Informalidad y dualismo en la actividad manufacturera mexicana. } \\
\text { Índice de Herfindahl Normalizado, por tamaño de unidades productivas. } \\
\text { 1994-2009 }\end{array}$} \\
\hline & \multirow[b]{2}{*}{ Herfindahl normalizado } & \multicolumn{2}{|c|}{ Unidades } & \multicolumn{2}{|c|}{ Personal } & \multicolumn{2}{|c|}{$F B C F$} & \multicolumn{2}{|c|}{ V. Agreg. } & \multicolumn{2}{|c|}{ Remun. } \\
\hline & & 1994 & 2009 & 1994 & 2009 & 1994 & 2009 & 1994 & 2009 & 1994 & 2009 \\
\hline \multirow{5}{*}{ 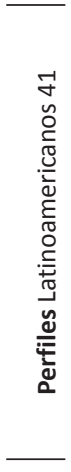 } & $\begin{array}{l}31 \text { Productos alimenticios, bebidas } \\
\text { y tabaco }\end{array}$ & 0.74 & 0.73 & 0.07 & 0.08 & 0.23 & 0.23 & 0.15 & 0.27 & 0.18 & 0.14 \\
\hline & $\begin{array}{l}32 \text { Textiles, prendas de vestir e } \\
\text { industria del cuero }\end{array}$ & 0.58 & 0.67 & 0.09 & 0.05 & 0.19 & 0.23 & 0.13 & 0.12 & 0.16 & 0.13 \\
\hline & $\begin{array}{l}33 \text { Industrias de la madera y } \\
\text { productos de madera. Incluye } \\
\text { muebles }\end{array}$ & 0.72 & 0.73 & 0.09 & 0.09 & 0.11 & 0.09 & 0.12 & 0.07 & 0.16 & 0.06 \\
\hline & $\begin{array}{l}34 \text { Papel y productos de papel, } \\
\text { imprentas y editoriales }\end{array}$ & 0.44 & 0.55 & 0.07 & 0.08 & 0.31 & 0.31 & 0.11 & 0.25 & 0.13 & 0.20 \\
\hline & $\begin{array}{l}35 \text { Sustancias químicas, productos } \\
\text { derivados del petróleo y del } \\
\text { carbón de hule y de plástico }\end{array}$ & 0.08 & 0.11 & 0.12 & 0.14 & 0.24 & 0.22 & 0.14 & 0.23 & 0.16 & 0.21 \\
\hline \multirow[t]{5}{*}{166} & $\begin{array}{l}36 \text { Productos minerales no metá- } \\
\text { licos. Excluye los derivados del } \\
\text { petróleo y del carbón }\end{array}$ & 0.68 & 0.68 & 0.05 & 0.06 & 0.23 & 0.29 & 0.19 & 0.22 & 0.15 & 0.12 \\
\hline & 37 Industrias metálicas básicas & 0.08 & 0.09 & 0.20 & 0.17 & 0.21 & 0.30 & 0.24 & 0.35 & 0.24 & 0.24 \\
\hline & $\begin{array}{l}38 \text { Productos metálicos, maquinaria } \\
\text { y equipo. Incluye instrumentos } \\
\text { quirúrgicos y de precisión }\end{array}$ & 0.54 & 0.64 & 0.11 & 0.16 & 0.22 & 0.29 & 0.17 & 0.28 & 0.17 & 0.25 \\
\hline & 39 Otras industrias manufactureras & 0.64 & 0.71 & 0.10 & 0.08 & 0.25 & 0.26 & 0.13 & 0.20 & 0.22 & 0.19 \\
\hline & Total manufactura & 0.62 & 0.67 & 0.06 & 0.06 & 0.19 & 0.22 & 0.12 & 0.20 & 0.15 & 0.17 \\
\hline
\end{tabular}

Fuente: Cálculos propios basados en: INEGI: Censos económicos. Resultados definitivos, 1994-2009.

ramas 36 (productos minerales no metálicos...), 38 (productos metálicos, maquinaria y equipo) y 71 (otras industrias manufactureras).

En el cuadro 7 observamos, en las columnas de "Unidades Económicas", un alto valor del Herfindahl normalizado, lo cual se debe a la gran concentración del número de empresas en las de 0 a 5 trabajadores en el total. La excepción la constituyen la rama de "Sustancias químicas, productos derivados del petróleo y del carbón de hule y de plástico" y la de "Industrias metálicas básicas", donde el peso de las empresas con 0 a 5 trabajadores es considerablemente menor y se redujo entre 1994 y 2009.

El valor del índice es bajo en lo relativo al personal ocupado, lo cual refleja que el empleo está menos concentrado en un tipo de empresas que en el número de unidades. La excepción es nuevamente la rama 35 (“Sustancias químicas, productos derivados del petróleo y del carbón de hule y de plástico") y la 37 (“Industrias metálicas básicas"). En ambas ramas, la mayor parte del empleo lo realizan las empresas grandes. 
Cuadro 7

Tasa de crecimiento Herfindahl

\begin{tabular}{lccccc}
\hline & Unidades & Ocupados & FBCF & V.A & Remun. \\
\hline 31 Productos alimenticios, bebidas y tabaco & -0.04 & 0.07 & -0.08 & 1.59 & -0.80 \\
\hline 32 Textiles, prendas de vestir e industria del cuero & 0.42 & -1.78 & 0.48 & -0.15 & -0.70 \\
\hline $\begin{array}{l}33 \text { Industrias de la madera y productos de madera. } \\
\text { Incluye muebles }\end{array}$ & 0.03 & -0.24 & -0.62 & -1.67 & -2.82 \\
\hline 34 Papel y productos de papel, imprentas y editoriales & 0.64 & 0.29 & 0.04 & 2.49 & 1.14 \\
\hline $\begin{array}{l}35 \text { Sustancias químicas, productos derivados del petró- } \\
\text { leo y del carbón de hule y de plástico }\end{array}$ & 0.92 & 0.51 & -0.34 & 1.48 & 0.70 \\
\hline $\begin{array}{l}36 \text { Productos minerales no metálicos. Excluye los deri- } \\
\text { vados del petróleo y del carbón }\end{array}$ & 0.00 & 0.53 & 0.65 & 0.43 & -0.51 \\
\hline 37 Industrias metálicas básicas & 0.53 & -0.57 & 1.01 & 1.03 & 0.05 \\
\hline $\begin{array}{l}38 \text { Productos metálicos, maquinaria y equipo. Incluye } \\
\text { instrumentos quirúrgicos y de precisión }\end{array}$ & 0.47 & 1.21 & 0.88 & 1.51 & 1.09 \\
\hline 39 Otras industrias manufactureras & 0.29 & -0.76 & 0.05 & 1.13 & -0.34 \\
\hline Total manufactura & 0.22 & -0.16 & 0.44 & 1.42 & 0.41 \\
\hline
\end{tabular}

En la formación bruta de capital fijo aparecen índices moderadamente elevados, lo que indica una relativamente alta concentración de la inversión, la cual se realiza predominantemente en las empresas con más de 250 trabajadores. Éstas son las responsables de más de 50\% de la inversión, exceptuando las ramas 32 ("Textiles, prendas de vestir e industria del cuero"), 33 ("Industrias de la madera y productos de madera. Incluye muebles") y 39 ("Otras industrias manufactureras"), en las que son más importantes las empresas medianas. Valores altos del índice y estructura similar se obtuvo para el valor agregado censal, pues se consiguió un índice análogo al de formación bruta de capital fijo. Esta similitud de las dos variables sugiere la estrecha relación entre la dotación de capital y la productividad, aspecto que se presenta más adelante. Los valores bajos del índice en la variable valor agregado en las ramas textiles, prendas de vestir e industria del cuero, en industrias y productos de madera, y en otras industrias, sugiere un mayor peso de las plantas de tamaño medio, y posiblemente bienes de capital de menor o más variado costo, quizás por economías de escala menores.

En el cuadro 8 se ilustran los cambios del índice entre 1994 y 2009. La trayectoria de las tasas de crecimiento es muy diversa y no es factible extraer de ella una regla. Por ejemplo, en casi todas las ramas se verificaron aumentos de la concentración en el número de empresas (salvo en las ramas 31 y 37), pero el índice se redujo en empleo (menos las ramas 31, 34, 35 y 36) y en FBCF. En la inversión también predominó la tendencia a la perdida 
de concentración y al aumento en las ramas 32, 34, 36, y 37. En cambio, en el rubro de valor agregado se dio una tendencia a la concentración en casi todas las ramas, salvo en la 32, la 33 y la 38.

La concentración en variables como formación bruta de capital fijo y valor agregado bruto, se presenta en las grandes empresas; en las demás variables su peso es relativamente menor, pero importante y creciente.

Realizamos un sencillo ejercicio de correlaciones simples, para detectar tres variables: la dirección de la relación entre las inversiones en capital fijo por trabajador y el tamaño de las empresas; la relación entre las inversiones y la productividad, y la relación entre la formación de capital y las remuneraciones. No se pretende encontrar una relación causal excluyente, dados los numerosos factores que inciden en la decisión de invertir. Sólo se pretende ilustrar si la vinculación entre las variables va en la dirección supuesta: cuando el tamaño de la unidad productiva es mayor, son superiores las inversiones por trabajador; y conforme estas últimas sean más considerables, mayores serán la productividad y las remuneraciones. Es necesario hacer estudios más detallados para determinar las causas de las inversiones y las razones por las cuales en México éstas han sido relativamente bajas desde los años ochenta; no se han reflejado ni en elevación de la dotación de capital por trabajador ni para el conjunto de las empresas de mayor tamaño, supuestamente las más modernas y vinculadas con el

\section{Gráfica 2}

Correlación entre el tamaño de unidades productivas y la formación bruta de capital fijo por trabajador en pesos constantes de $\mathbf{2 0 0 0}$

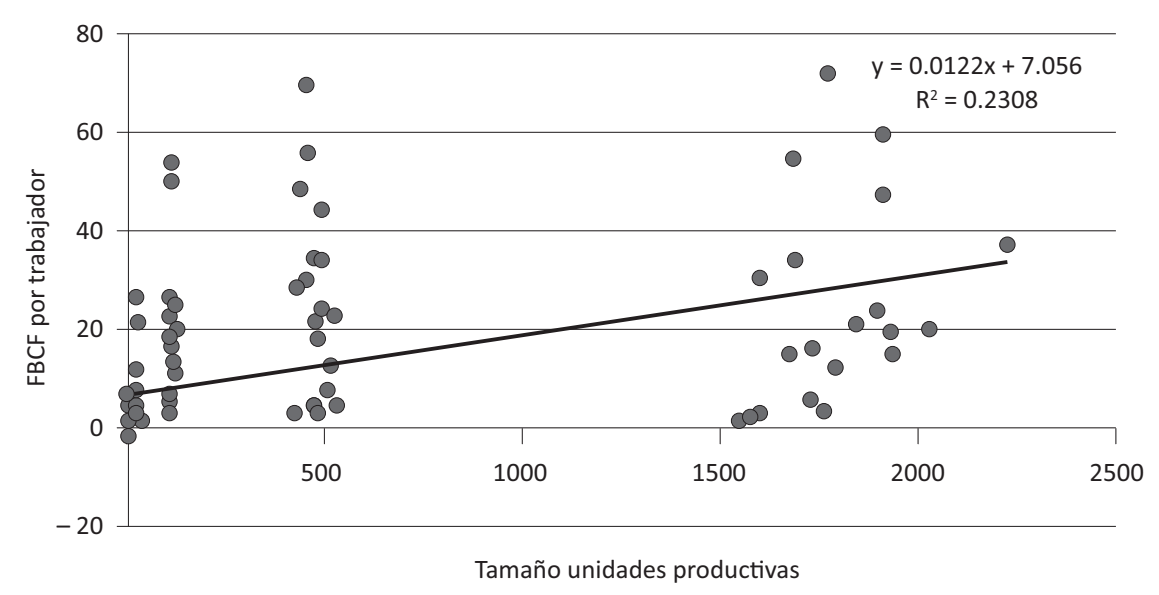


Gráfica 3

Correlación entre el valor agregado por trabajador y la formación bruta de capital fijo en pesos de $\mathbf{2 0 0 0}$

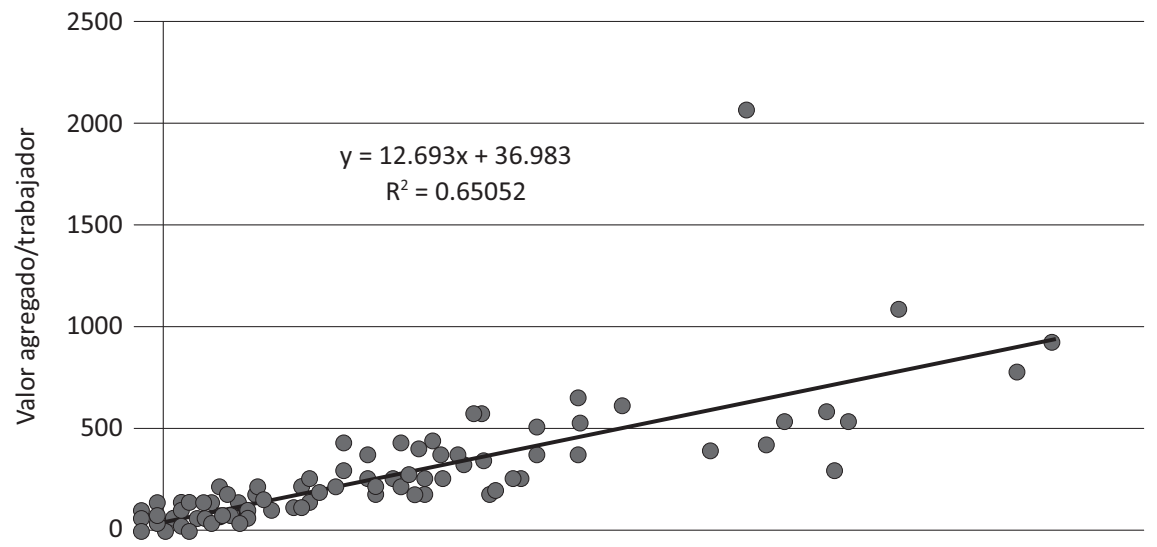

FBCF/trabajador

\section{Gráfica 4}

Correlación entre las remuneraciones por trabajador y la formación bruta de capital fijo en pesos de $\mathbf{2 0 0 0}$

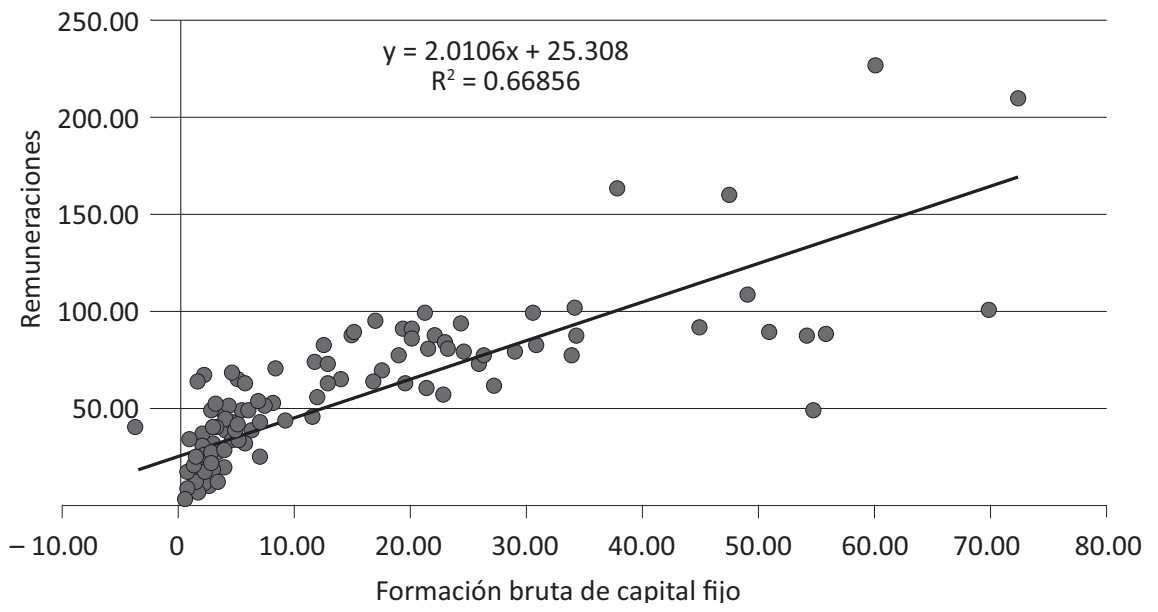


comercio internacional. Los resultados obtenidos sugieren, en primer lugar y como se esperaba, una relación directa entre la formación bruta de capital fijo y el tamaño de las empresas, medido por número de trabajadores. El valor del R cuadrado es relativamente bajo y sólo explicaría 25\% de la variación. Para el conjunto del sector manufacturero, entre mayor es el tamaño de la empresa, mayores son las inversiones por trabajador. Esta relación es mucho más acentuada en ramas específicas, como la química, la petroquímica y la automotriz. La gráfica 2 ilustra, para el año 2008, la relación entre la formación bruta de capital fijo por trabajador (miles de pesos constantes del 2000) en cada tamaño de planta para toda la industria manufacturera mexicana (eje vertical), y el tamaño promedio de empresa en cada una de las siete grandes ramas. En dos dígitos de la Clasificación Internacional Industrial Unificada (CIIU), se divide la industria manufacturera para 2008 (eje horizontal). Igual correlación positiva y más fuerte se obtuvo para la inversión por trabajador y la productividad (valor del R cuadrado 65) (gráfica 3), y entre aquélla y las remuneraciones por trabajador (valor del R cuadrado 65) (gráfica 4).

Se desprende una conclusión interesante: a mayor tamaño de los establecimientos, medido por el número de trabajadores, mayor es su inversión por trabajador y mayores son la productividad y las remuneraciones que ofrecen a sus trabajadores. Esto pone en evidencia el papel de la inversión como factor explicativo de la formalidad, y la insuficiencia de ésta como fuente de la informalidad y como razón de la permanencia del dualismo en los términos de Lewis. En México, la limitada dinámica del sector formal o moderno, y la de las inversiones, no ha generado la demanda de empleo indispensable para elevar la productividad del trabajo y sus remuneraciones, y para absorber el empleo de los establecimientos informales. ${ }^{8}$ Pero hemos visto que aún los establecimientos de más de mil trabajadores han invertido poco y perdido dotación de capital por trabajador. Resulta pertinente, por lo tanto, preguntar qué efectos tiene la débil actividad inversionista de las grandes y las medianas empresas sobre todo el sector y sobre su capacidad de elevar la productividad y su demanda de trabajo, y para inducir la transferencia de trabajo del sector no moderno al moderno.

8 Este ejercicio requiere de series de tiempo más largas y trabajar con acervos de capital u otra variable de activos, y aplicar métodos de panel, lo que sobrepasa los objetivos de este trabajo. 


\section{Conclusiones}

Este ensayo analizó la informalidad y el dualismo en el sector manufacturero, a partir de la información suministrada por el INEGI en sus Censos económicos. Resultados definitivos, la cual se comparó, en algunos aspectos, con los datos de las Encuestas Nacionales de Micronegocios (Enamin). Se cubrió el periodo 1994-2004, en el que se consolidaron los efectos de las reformas estructurales, de la liberalización comercial y del TLCAN. Se concentró en el estudio de la estructura del sector manufacturero, discriminado la capacidad instalada según el tamaño de empresas, para identificar las equiparables al sector formal. El INEGI define como informales los establecimientos de 15 o menos trabajadores, y formales el resto, y ese mismo tamaño es el que utilizan las Enamin para determinar el universo de los micronegocios. Los censos suministran información, para cada tipo de empresas, en siete variables: número de empresas, empleo, producción bruta, formación bruta de capital fijo, valor agregado y remuneraciones.

Partimos del modelo de Lewis sobre crecimiento con ilimitada mano de obra en economías abiertas, donde coexisten un sector moderno, capitalizado y con salarios rígidos, y el sector no moderno, con baja dotación de capital y salarios no rígidos y bajos costos de entrada. Este último sector se nutre de la mano de obra que emigra de las áreas rurales y de la agricultura, y alimenta la oferta de mano de obra urbana que, en teoría, satisfaría la demanda del sector moderno o formal. Esta oferta de mano de obra garantiza el crecimiento del sector formal sin que haya inflación. En la medida en que crece el sector moderno gracias a la inversión de las utilidades, se drena mano de obra del sector no moderno de la agricultura, hasta que empiecen a elevarse los salarios reales. Se supuso que este proceso se aceleraría con la liberalización de la economía. Lewis sugirió que no toda la mano de obra que emigra a las ciudades encuentra empleo en el sector moderno, por lo que se emplea en los pequeños negocios de servicios y manufacturas, el empleo por cuenta propia, el familiar y el doméstico, con lo que, sugiere el autor, el dualismo se traslada a las urbes.

La trayectoria del sector manufacturero mexicano, durante 1994-2009, alienta muchas reservas en torno a la solidez del modelo exportador, basado en las ventas externas de manufacturas producidas en unidades insertas en las cadenas de valor mundiales.

La teoría asumía que el comercio internacional induciría cambios esenciales en la estructura productiva, la productividad, el empleo y las remuneraciones. Al vincular los precios internos y los externos, se induciría la transferencia de factores hacia las actividades más eficientes, en términos 
internacionales, y crecería la productividad. Los aumentos en productividad generarían las condiciones propicias para el crecimiento productivo y acarrearían superiores inversiones en los sectores transables. Este proceso, según Lewis, induciría la transferencia de empleo del sector atrasado o no moderno hacia el moderno, y la informalidad sería absorbida por las actividades formales o modernas.

A17 años de iniciada la instrumentación del TLCAN y a casi tres décadas de las reformas estructurales, no parece que el anunciado movimiento de los factores hacia los sectores transables más eficientes se haya realizado, como tampoco el traslado de la mano de obra del sector informal al formal en las ciudades. Sí se verificó un intenso movimiento de mano de obra del sector agrícola y del campo a la ciudad, lo que ha redundado en el abultamiento del empleo informal urbano.

En las ciudades, la informalidad ronda el $60 \%$ del empleo total y se concentra en el sector servicios, en los trabajadores por cuenta propia y en micro-establecimientos. Las manufacturas dan cobijo a cerca de $25 \%$ del empleo informal que labora en una proporción considerablemente mayor (94\%) de establecimientos. La informalidad, tanto en número de unidades productivas como en empleo, creció en el periodo estudiado en una trayectoria opuesta a la formación bruta de capital fijo o en el valor agregado, que tuvieron crecimiento negativo.

La estructura de las manufacturas presenta una sensible atrofia, con más de $90 \%$ de unidades productivas de menos de 15 trabajadores y cuyo tamaño promedio es de 2.8 trabajadores. En este conjunto de empresas predominan las microunidades, o sea, las de uno a cinco trabajadores. Este predominio de las microempresas en el total de la informalidad, y de ésta en la estructura manufacturera, señala las dificultades encontradas para realizar una política sectorial uniforme y una integración de las cadenas productivas que incluya a este sector y no se concentre exclusivamente en las más grades. Hay que recordar, además, que la informalidad ha crecido a la vez que se ha angostado la participación de las empresas pequeñas (entre 16 y 50 trabajadores) en todas las variables formación bruta de capital y valor agregado, por lo que se acercan a las informales. Una evolución similar se registró para las medianas empresas (de 50 a 250 operarios). La evolución de la estructura manufacturera apunta a una intensificación del dualismo y a una mayor distancia en las variables económicas entre el sector formal y el informal, o entre el moderno y el atrasado, distancia que resultará muy difícil reducir. Una de las razones de la supervivencia del dualismo es la escasa actividad inversionista que registramos para todos los tamaños de empresas y para el conjunto del sector manufacturero, y llama la atención 
que a todo lo largo y ancho de la estructura se haya reducido la dotación de capital fijo por trabajador. Esa caída fue más intensa en las empresas más pequeñas. El decaimiento de la inversión tiene que ver con la limitada dinámica del valor agregado total y por trabajador.

En nuestra perspectiva, la FBCF es una variable central en el desarrollo de las manufacturas, y explica tanto el lento crecimiento de la productividad como la evolución de las remuneraciones totales y por trabajador durante el periodo 1994-2009. Constatamos que a mayor tamaño de las empresas tiende a ser superior la inversión fija, y a mayor ésta, superiores son el valor agregado y las remuneraciones.

La integración de las cadenas productivas y la expansión del sector manufacturero formal, que permitirían absorber el trabajo acumulado en el sector atrasado en tal magnitud que induzca la elevación de los salarios reales totales, demanda, en primer lugar, acciones encaminadas a eliminar los mecanismos que han desalentado las inversiones en el sector manufacturero; en segundo término, exige la capacitación de la mano de obra para elevar su capacidad de integrarse a las actividades más dinámicas, y en tercer lugar, demanda inversiones en desarrollo tecnológico, para que el sector pueda apropiarse de la moderna tecnología acorde con la amplia inserción en el mercado global y le permita, por un aparte, añadir mayor valor agregado a las exportaciones manufactureras y, por el otro, competir y evitar el desalojo de los mercados de destino de sus ventas externas. Estas acciones deben permitir igualmente una más elevada eficiencia productiva de los productos importables, es decir, de los bienes nacionales manufacturados que compiten con las importaciones, de suerte que resistan la competencia y se amplíe su participación en el mercado nacional y en la satisfacción de la demanda interna.

\section{Bibliografía}

Banco Mundial, 2004a, Doing business in 2004: Understanding regulation, Washington, Banco Mundial.

Banerjee, B., 1983, “The Role of the Informal Sector in the Migration Process: A Test of Probabilistic Migration Models and Labour Market Segmentation for India", Oxford Economic Papers, 35 (3), pp. 399-422.

Cervantes, J., E. Gutiérrez y L. Palacios, 2009, “El concepto de economía informal y su aplicación en México: factibilidad, inconvenientes y propuestas", Estudios 
Demográficos y Urbanos, vol. 23, núm. 1 (67), pp. 21-54, http:/ / www.manuelcuellarrio.org/economiainformal.PDF

Daniels, P.W., 2004, "Urban challenges: the formal and informal economies in megacities", Cities, núm. 21 (6), pp. 501-511.

De Soto, H., 1989, The Other Path, Nueva York, Harper \& Row.

Escaith, H., 2006, “Industrialización truncada y terciarización sustitutiva en América Latina", Problemas del Desarrollo, vol. 37, núm. 147, pp. 47-80

Esquivel y Ordaz Díaz, 2009, ¿Es correcto vincular la política social a la informalidad en México? Una prueba simple de las premisas de esta hipótesis, Gerardo Esquivel y Juan Luis Ordaz Díaz (LC/L.2989-P (LC/MEX/L.890)

Fiess, N., Marco Fugazza y William Maloney, 2002, “Exchange Rate Appreciations, Labor Market Rigidities, and Informality", World Bank.

Galli, R. y D. Kucera, 2004, "Labor Standards and Informal Employment in Latin America”, World Development, núm. 32 (5), pp. 809-828.

Garro et. al., 2005, “Un modelo del mercado laboral mexicano con trabajo con o sin seguro social (IMSS)", serie Documentos de Investigación, México, D.F., IIDES, Universidad Iberoamericana.

Gurleen K., Popli, 2009, "Trade Liberalization and the Self-employed in Mexico", UNO-WIDER, Research Paper núm. 2009/05.

Gutiérrez-Romero, Roxana, 2010, “The Dynamics of the Informal Economy”, Oxford University, CSAE WP/ 2010-07.

INEGI, 1995 y 2009a, Censos Económicos y Encuestas. Resultados Definitivos, 1994 y 2008.

INEGI, 2009b, Encuesta de Micronegocios, 2008, consultada el 20 de mayo del 2011, en http://www.inegi.org.mx/prod_serv/contenidos/espanol/bvinegi/productos/encuestas/establecimientos/enamin/2008/Enamin_2008.pdf

Kaldor, N., 1968, "Productivity and Growth in Manufacturing Industry: A Reply", Economica, núm. 35, pp. 385-390.

Kaldor, N., 1975, “Economic Growth and the Verdoorn's law. A Comment on Mr. Rowthorn's Article", Economic Journal, núm. 85, pp. 891-896. 
Kirkpatrick, C. y A. Barrientos, 2004, “The Lewis Model After Fifty Years”, Universidad de Manchester, Development Economics and Public PolicyWorking Paper Series, WP núm. 9, September 2004.

Knight, J., 2007, “China, South Africa and the Lewis Model”, Research Paper núm. $2007 / 82$

La Porta, Rafael y Andrei Shleifer, 2009, “The Unofficial Economy and Economic Development", NBER Working Paper núm. 14520.

Levy, S., 2007, “¿Pueden los programas sociales disminuir la productividad y el crecimiento económico? Una hipótesis para México", El Trimestre Económico, vol. LXXIV, núm. 3, pp. 491-540.

Levy, S., 2008, Buenas intenciones, pobres resultados: política social, informalidad y crecimiento económico en México, Brookings Institution Press, 2008.

Levy, S., 2011, "Hacia una seguridad social para todos", entrevista en El Economista, mayo 31, consultado en http://eleconomista.com.mx/finanzas-publicas/2011/05/31/proponen-seguridad-social-universal

Lewis, W. A., 1958, “Economic Development with Unlimited Supplies of Labour", en Theodore Morgan (ed.), Readings in economic development, Belmont, Wadsworth, 1963.

Lewis, W. A., 1979, "The Dual Economy Revisited", The Manchester School, vol. 47, núm. 3, pp. 211-229.

López-Acevedo, G. y A. Salinas, 2000, “Marginal willigness to pay for education and the determinants of enrollment in Mexico. Policy Research", Working Paper 2 405, Washington, Banco Mundial.

McCulloch, N., G., G. Schulze, Voss Günther Schulze y J. Voss, 2010, ¿What Determines Firms' Decisions to Formalize?, Discussion Paper Series, núm. 13, University of Freiburg, Department of International Economic Policy.

Maloney, W., 1997, “Labor Market Structure in LDCs Time Series Evidence on Competing Views", en International Bank for Reconstruction and Development Working Paper, 1940.

Maloney, William F., 2004, “Informality Revisited”, World Development, núm. 32 (7), pp. 1159-1178. 
Maloney, William F., 1999, "Does informality imply segmentation in urban labor market? Evidence from sectoral transitions in Mexico", The World Bank Economic Review, núm. 13 (2).

Palma, G., 2011, “Homogeneous Middles vs. Heterogeneous Tails, and the End of the 'Inverted-U': It's All About the Share of the Rich", Development and Change, vol. 42, núm. 1, pp. 87-153.

Palma, G., 2009, “The Revenge of the Market on rentiers: Why neo-liberal reorts of the end ho history turned out to be premature", Cambridge Journal of Economics, vol. 33, núm. 4 .

Portes, A., et al., 1989, The Informal Economy: Studies in Advanced and Less Developed Countries, editado por Alejandro Portes, Manuel Castells y Lauren A. Benton, Baltimore, Md.: Johns Hopkins University Press.

Puyana, A., 2011, “Economic growth, employment and poverty reduction: A comparative analysis of Chile and Mexico", ILO, Employment Working Paper núm. 78.

Puyana, A. 2009, “Apertura, crecimiento, productividad y empleo en América Latina, 1980-2002. Un análisis sobre los efectos de la inserción en la economía internacional en Argentina, Brasil, Chile, Colombia, Costa Rica y México", Flacso, 2009.

Puyana, A. y J. Romero, 2009, México. De la Crisis de la deuda al estancamiento económico, México, D.F., Colmex.

Ranis, G., 2004, “Arthur Lewis. Contribution To Development Thinking And Policy", Discussion paper núm. 891, Yale University, Economic Growth Center, http://www.econ.yale.edu/ egcenter/

Rodríguez-Oreggia, 2006, "Análisis de la informalidad en México y sus premios salariales", Boletín de los Sistemas Nacionales Estadísticos y de Información Geográfica, vol. 2, núm.1, enero-abril, México, D.F.

Rodríguez-Oreggia, 2007, "La dinámica comparativa del sector informal en México", serie Documentos de Investigación, IIDES, México D.F., Universidad Iberoamericana.

Schneider, F., y D.H. Enste, 2000, “Shadow Economies: Size, Causes, and Consequences", Journal of Economic Literature, núm. 38 (1), pp. 77-114. 
Thirlwall, 1983, “A Plain Man's Guide to Kaldor's Growth Law”, Journal of Post Keynesian Economics, pp. 345 - 358.

Todaro, M., 1969, “A model of labor migration and urban unemployment in less developed countries", American Economic Review, núm. 59 (1), pp. 139-148.

Recibido el 20 de agosto de 2011 Aceptado el 30 de septiembre de 2012 
